\title{
DESAFIOS DA SOCIOLOGIA DA INFÂNCIA:
} UMA ÁREA EMERGENTE

\author{
Cleber Fabiano da Silva, Tânia Regina Raitz e Valéria Silva Ferreira \\ Universidade do Vale do Itajaí, Itajaí, Brasil
}

\begin{abstract}
RESUMO: Este ensaio teórico discute os desafios da Sociologia da Infância na contemporaneidade como uma área emergente para se pensar a prática docente com crianças. Para tanto, aborda as mudanças que ocorreram ao longo do tempo. Em cada momento histórico e social há influências contextuais das produções sobre a temática, portanto, tais mudanças são absorvidas de modos diversos, dependendo de cada um desses períodos. Neste sentido, é necessário um olhar atento para a heterogeneidade das experiências sociais e das expressões culturais que introduzem novas lógicas de ação no cerne das transformações em curso nas sociedades contemporâneas, especialmente em relação à infância. A partir de dados recentes de duas pesquisas sobre formação de professoras da educação infantil, refletimos sobre um novo olhar que aborde as crianças também como atores sociais e as especificidades da docência de zero a seis anos.
\end{abstract}

PALAVRAS-CHAVE: sociologia da infância; educação infantil; prática docente.

\section{CHALLENGES OF THE SOCIOLOGY OF INFANCY: AN EMERGENT AREA}

ABSTRACT: This essay discusses the theoretical challenges of the contemporary sociology of childhood as an emerging field to think about the practice of teaching children. To do so, it addresses the changes that have occurred over time. In each historical and social moment there are contextual influences of production on the subject, so these changes are absorbed in different ways, depending on each of these periods. In this sense, we need a watchful eye to the heterogeneity of social experiences and cultural expressions that introduce new logic of action at the heart of the ongoing transformations in contemporary societies, especially in relation to childhood. From recent data from two surveys on the training of kindergarten teachers, we reflect on a new look to raise children also as social actors, and the specificities of teaching children from zero to six years old.

KEYWORDS: Sociology of Infancy, Childhood Education, Teaching Practice.

\section{Introdução}

O estudo de Philippe Ariès (1981), intitulado "História social da criança e da família", constitui-se, conforme Peralva (1997), o marco inaugural que destaca as idades da vida - infância, adolescência e juventude - não mais como fenômenos naturais, mas imbuídas de caráter social e histórico. Ariès desenvolve suas argumentações apresentando os vínculos particulares que ligavam crianças e adultos nos períodos moderno e pré-moderno. Os elementos constituintes da sociedade medieval mostram a separação entre o mundo infantil e o adulto, bem como o processo simultâneo de separação do espaço familiar em relação ao universo social mais abrangente. A fase de transição no desenvolvimento social do indivíduo ocorria sem grandes rupturas, sem grandes destaques. Embora alguns críticos de Ariès, segundo Heywood (2004), considerem exagero dizer que na idade média inexistia o sentimento de infância. Este autor diz que na idade média o conceito de infância era tão distinto do que conhecemos atualmente que não conseguimos reconhecê-lo.

Mesmo assim, o reconhecimento social da infância e da adolescência passa a ser evidente no século XVIII, num contexto marcado por uma economia mercantil ainda em fase de expansão. Nesse contexto, era notório o processo aberto de troca que cada um deveria participar, de bens e de compra e venda da força de trabalho. A família era fundada na autoridade paterna, tinha como dever a conservação do patrimônio - herança - e o prolongamento da linhagem. O crescimento demográfico e a concentração urbana iriam acentuar as condições para algumas mudanças, em que a educação começa a assumir um papel crucial, após a passagem que afirmou a posição dominante da burguesia. Assim, no século XIX, começa a elaboração do cerco institucional para esta fase da vida - adolescência - que a torna cada vez mais específica em processos de aprendizagem profissional.

Varela e Uria (1992), ao esboçarem as condições sociais do aparecimento de várias instâncias, que são 
fundamentais para entender o surgimento das escolas no princípio do século XIX, relatam que para as crianças das classes mais poderosas estava resguardada a tutela através da família e do colégio, já para os pobres bastava uma: a das instituições de caridade, que os mantinham afastados de suas famílias, apenas com atendimento esporádico. A descrição que fazem os referidos autores, da maneira que era imposto o ensino na época para as classes mais pobres, revela hábitos e costumes que se propagavam como um

ensino rudimentar, para gente rude e ignorante, sem a finalidade de acesso à cultura, senão inculcar estereótipos e valores morais em oposição aberta às formas de vida das classes populares. Sobretudo impor-lhes hábitos de limpeza, regularidade, compostura, obediência, respeito à autoridade, etc. (Varela \& Uria, 1992, p. 15).

Tais práticas educativas, familiares e institucionais, impõem uma vigilância multiforme também aos jovens. A educação, como projeto, passa a estabelecer a diferenciação entre as classes sociais, envolvendo o trabalho. Os espaços institucionais fechados e idealizados pelos moralistas servirão, de acordo com os autores, "de maquinaria" de transformação da juventude, estes irão diferenciar as disciplinas, abrandar, enfim, os destinos de seus usuários. Assim, de acordo com cada momento histórico, existem influências contextuais absorvidas nas produções sobre a temática. Obviamente sendo os jovens e as crianças vistos como sujeitos histórico-sociais, a realidade e as análises não devem se manter estáticas durante o passar dos anos, portanto, estas mudanças são absorvidas de modos diversos, dependendo de cada momento histórico. Este estudo propõe observar esta perspectiva a partir da prática atual de educadores na educação infantil.

O presente em forma de ensaio teórico visa discutir os desafios postos à Sociologia da Infância como uma área emergente na atualidade, para refletir sobre a prática docente na educação infantil a partir da necessidade de um olhar diferente por meio da Sociologia da Infância. Com base no que foi exposto, surgem algumas indagações consideradas importantes para discorrer a respeito dos estudos da Sociologia da Infância: que tipo de escola seria interessante para as crianças? Quais atividades são importantes para o seu desenvolvimento? Qual o currículo significativo para a infância? Em síntese, este artigo propõe trazer aspectos para uma reflexão a respeito de quais elementos são relevantes na prática docente.

\section{Sociologia da Infância e novos processos socializadores}

Estaríamos hoje vivendo novo entendimento dos processos socializadores contemporâneos, diferente- mente dos paradigmas abordados pela sociologia clássica, vista por Durkheim - estudos sobre socialização - e Weber (1982) - estudos sobre as lógicas de ação. Muitos autores vêm questionando a centralidade de agências tradicionais socializadoras como a família, a escola e o trabalho e as lógicas de ação ou de conduta que as orientam, estas estariam passando por crises e ganhando novos significados (Colbari, 1995; Dayrell, 2003; Dubet \& Martuccelli, 1999; Pais, 1993; Sposito, 1997; Zaluar, 1985).

Sugere-se, assim, um olhar atento para a heterogeneidade das experiências sociais e das expressões culturais que introduzem novas lógicas de ação no cerne das transformações em curso nas sociedades contemporâneas. Como explicita Pais (1993), a maneira como os jovens, bem como as crianças vêm sendo socializadas, quer pela família, quer pela escola, pelo trabalho, pelas diversas experiências alimentadas por suas expectativas futuras, resultantes muitas vezes de processos de socialização, não sinaliza mais uma correspondência unívoca com a realidade que eles esperam. Nas oportunidades de emprego, tipos de trabalho, lazeres, sociabilidades, constituição das famílias, parece emergir novas formas de interação orientando as lógicas de ação.

Conforme o autor, as mutações decorrentes nas sociedades atuais provocam deslocamentos das fronteiras antes delimitadoras dos campos de ação das mencionadas instituições, estando mais sujeitas a desmoronamentos, ainda que persistam suas lógicas disciplinadoras. A tendência mesmo é se dispersar de maneira mais fluída por todo o tecido social. Os muros que garantiam uma autonomia destas instituições encontram-se colocados em xeque. Fica cada vez mais difuso distinguir o fora e o dentro destas agências. $\mathrm{O}$ problema passa pela própria definição dos poderes e campos de ação.

Dubet (1994, citado por Charlot, 2000) aponta ideias para estas reflexões quando constrói o conceito de "experiência social escolar", considerando a questão da subjetividade. Este autor afirma que a noção de "ação" central na sociologia clássica não é mais relevante para entender uma vida social que sofre cada vez mais um amplo processo de fragmentação, mostrando a impossibilidade de reduzir a sociologia ao estudo das posições sociais. Neste sentido, critica a sociologia clássica em sua visão de sociedade como unidade funcional - o ator seria o sistema. Sendo assim, apenas interioriza as normas e os valores sociais em posições definidas no seu interior.

Essa sociologia não mais satisfaz, uma vez que apenas explica os indivíduos a partir de determinados lugares específicos no sistema, deixando de lado a subjetividade que os engendra. Os atores e as instituições não estariam mais reduzidos a uma única lógica, 
isto significa que as condutas sociais não se reduzem a meras aplicações de códigos interiorizados ou a cadeias de escolhas estratégicas, fazendo da ação uma série de decisões racionais. Essas condutas não estão diluídas no fluxo contínuo de uma vida cotidiana feita de interações sucessivas, elas não são mais organizadas por princípios estáveis, mas por princípios heterogêneos. É nesta heterogeneidade que o autor fala da experiência social que se define a partir da combinação de várias lógicas de ação. Sob este enfoque, o ator não seria mais socializado somente por orientações das instituições, consequentemente, sua identidade não seria construída apenas pelas marcas do sistema. Contudo, os indivíduos se constroem socialmente por meio das diversas experiências numa relação processual dinâmica (Melucci, 2004), significando que as crianças, alunos (as) da educação infantil, vivenciam várias experiências em seu cotidiano, não só na escola.

Segundo ainda Dubet e Martuccelli (1996, citado por Charlot, 2000), é a experiência social do indivíduo que constrói uma identidade, um significado para suas ações, sempre dialogando e articulando com as lógicas de ação que já se encontravam estabelecidas. Pelo exposto, concebe-se que, em seu conhecimento crítico da estrutura da sociedade, no encontro e desencontro entre si e os outros, como membros de vários grupos sociais com os quais eles mantêm relações complexas, de pertencimento e negação, de adequação, distância e de identificação, é que nascem as experiências heterogêneas.

Desse modo, ressalta-se que cada criança da educação infantil, neste caso, na escola que foi analisada, embora esteja inserida num determinado grupo social ou forma associativa, não se limita apenas a este vínculo como forma de pertencimento num espaço único da estrutura social. Não estão submetidas apenas a uma lógica de orientação. As crianças, adolescentes e jovens fazem parte de uma sociedade em processo de socialização recebendo, mensagens que estão disponibilizadas conforme suas necessidades, interesses e representações. Assim, as fontes e agências socializadoras clássicas como a escola, a família e o trabalho estariam mostrando certa fragilidade como referenciais de normas e valores, sendo que a família seria ainda uma instituição que continua como forte núcleo de referência formativa. Entretanto, não podemos esquecer que existe uma rede de pertencimentos que os identifica. Essa, por sua vez, constitui aquilo que se tem chamado de rede de significados dos processos identitários, em que o próprio ator, seja criança, adolescente ou jovem, interpreta e dá sentido a sua vida através de suas experiências, faz escolhas, age sobre sua realidade, sendo fruto de múltiplos processos.

\section{A emergente Sociologia da Infância}

O movimento que vem sendo construído no sentido de consolidar a Sociologia da Infância como um novo campo ou uma nova vertente da Sociologia da Educação, apesar de ainda disperso, com poucas interações, necessitando de mais circunscrições, está em vias de reconhecimento por uma gama de pesquisadores que se interessam pelo assunto. Essa é uma discussão pertinente e emergente, mostrando que a criança não é apenas promessa de futuro, um vir a ser, um ser incompleto, pelo contrário, ocupa um tempo e espaço importantes no presente, ultrapassando as análises que consideram esta faixa etária vinculada à passagem de uma fase para a vida adulta, ou apenas sua natureza biológica. A criança deve ser vista numa perspectiva histórico-social-cultural.

A emergente Sociologia da Infância tem tido essa preocupação, as crianças são atores sociais, participam das trocas, das interações, dos processos de ajustamento permanente que configuram e contribuem para transformar a sociedade. Elas estão inseridas na vida cotidiana, cuja análise não se reduz à das instituições. Além disso, na Sociologia da Infância, a criança tem sido vista como autora. Isso depende de como o educador resgata o aprendizado do aluno ou criança, especialmente na educação infantil, como poderemos observar nos resultados de pesquisa. São protagonistas como os adultos e educadores no sentido de que não são seres passivos à espera de que outros sempre os eduquem como vislumbrava os estudos da sociologia clássica representada pelos trabalhos de Durkheim (sobre socialização) e de Weber (sobre as lógicas de ação). Inúmeras são as transformações por que tem passado a sociedade, em todas as esferas que a compõem. Dessa forma, o inventar das crianças, muitas vezes, direciona a novas formas de sociabilidade, novas formas de expressões culturais que proliferam a cada dia.

Não obstante se defenda a vivência plena dessa fase, também não se pode pensar que esse tempo/espaço da criança seja como um mundo à parte, distante, sem conexão com outras realidades. Deve-se levar sempre em consideração que, além dos agenciamentos entre seus pares, também a criança está todo o tempo em contato com jovens, adultos e velhos, lendo e interagindo com o seu contexto. Para Sarmento (2005, p. 363), "a infância deve constituir-se como um grupo com um estatuto social diferenciado e não como uma agregação de seres singulares". Difícil estabelecer essa medida, pois o mesmo autor sinaliza que a ideia de uma representação social da infância pautada na imperfeição, na incompletude, na dependência e na transitoriedade, foi fortemente enraizada na humanidade através da Psicologia do desenvolvimento. 
Assim, uma das contribuições do autor para a Sociologia da Infância, estaria relacionada à inclusão do conceito de "geração" para a análise das relações sociais, nisto que essas relações intergeracionais têm constituído um aspecto vital na mudança social. Ele salienta que o seu objetivo é "historicizar o conceito de geração, sem perder de vista as dimensões estruturais e interacionais" e enfatiza:

A infância é historicamente construída a partir de um processo de longa duração que the atribuiu um estatuto social e que elaborou as bases ideológicas, normativas e referenciais do seu lugar na sociedade. Esse processo, para além de tenso e internamente contraditório, não se esgotou. É continuamente actualizado na prática social, nas interacções entre crianças e nas interacções entre crianças e adultos ... (Sarmento, 2005, p. 365)

Nesta perspectiva, o sujeito está em interação com outros sujeitos, busca sua própria construção e seu lugar no mundo, sua identidade pessoal e social. Por exemplo, ao se relacionar com os outros, a criança se transforma, mas ao mesmo tempo, os que se relacionam com ela também se modificam. Deve-se pontuar, sobremaneira, que a concepção de criança, sob o ponto de vista da Sociologia da Infância, não é propriamente recente, todavia, o que é novo é a inversão de como olhá-la. Conforme Ferreira (2002), ao assumir a autonomia conceitual ou a criança como categoria social, acaba defendendo que suas culturas e relações sociais são dignas de serem estudadas nelas mesmas, no presente, a partir das próprias vozes das crianças. Esta preocupação tem se traduzido em modos diferentes de construir sociologicamente a infância, tanto do ponto de vista teórico como metodológico.

A perspectiva de um novo olhar que aborda as crianças como atores sociais constitui-se num objetivo que coaduna com o dos pesquisadores que vêm se preocupando em (des) construir a universalidade do conceito de infância, neste sentido, tentando ultrapassar leituras meramente reducionistas que apenas enxergam a infância como um tempo de passagem para a vida adulta, como um ser passivo que acaba por ver a educação infantil também como simples preparação para a escolarização.

É importante ressaltar que uma das preocupações centrais da Sociologia da Infância é transcender o modo como nós, adultos, vemos e pensamos as crianças, visão que acaba por interferir no nosso relacionamento com elas. Não podemos esquecer que as crianças, sem sombra de dúvidas, são atores sociais dotados de pensamento crítico e reflexivo, por isso mesmo, chama-se a atenção para suas ações como prova de si. Ademais, aprofundar a reflexão para além das dimensões instrumentais, vislumbrar o entendimento dos processos nos quais as pessoas se formam ou podem vir a se formar humanamente (sobretudo as crianças). Isto requer outro caminho, que é colocar a reflexidade e a criatividade em jogo, com narrativas que permitem explicitar a singularidade das crianças e dos educadores, e com elas, viver o coletivo, perceber o caráter processual da formação e da vida. Neste sentido, articulando espaços, tempos e as diferentes dimensões de nós mesmos, em busca de uma sabedoria no tratamento da heterogeneidade que está posta no mundo contemporâneo. É nessa representação que aparecem os resultados das pesquisas em discussão quando apontam os desafios processuais e de articulação com os espaços e tempos diferentes da educação infantil.

\section{A prática docente com as crianças}

Parece ser consenso em nossa sociedade atual que a infância deve ser um período de vida para viver as brincadeiras e não pode ser ocupada no trabalho adulto. É um período exclusivo para frequentar a escola. Dessa forma, a escola e as práticas educativas com crianças são de evidente importância. Segundo Sarmento (2005, p. 367):

a sociologia da infância propõe-se a constituir a infância como objeto sociológico, resgatando-a das perspectivas biologistas, que a reduzem a um estado intermédio de maturação e desenvolvimento humano, e psicologizantes, que tendem a interpretar as crianças como indivíduos que se desenvolvem independentemente da construção social das suas condições de existência e das representações e imagens historicamente construídas para eles.

A Psicologia do Desenvolvimento, numa perspectiva histórico-cultural, concebe a infância como um período fundamental no desenvolvimento humano. Portanto, a escola assume um papel de destaque, principalmente como agência promotora de interações sociais. Nesta perspectiva, o processo de escolarização é positivo para o desenvolvimento humano. Para Ferreira (2002), as crianças não deixam de se constituir em seres inteligentes, socialmente competentes e com capacidades para realizarem suas ações, ademais, possuem emoções e sentimentos à luz das suas próprias evidências. Isto tudo requer do educador ou da escola outra atenção para além da mera observação. A escuta deve ser uma dinâmica diária, além do papel de um intérprete e tradutor competente e coerente das crianças, partindo de seus pontos de vista, como também dos significados que atribuem às situações que estão envolvidas. Por isso mesmo, a prática permanente deve ser a disposição em aceitar o inesperado, o improviso que as crianças trazem, os adultos e educadores precisam estar abertos no sentido de se surpreender com elas, com suas experiências e novidades. Porém, isto só será possível se os papéis tradicionais se inverterem e as lógicas de ação 
também, o que implica uma reflexão acerca das relações desiguais de poder entre adultos e crianças.

Pensar na educação da infância é um ponto de pouco consenso. Há os que defendem que, no período de educação infantil, o lugar das crianças não deve ser chamado de escola. Há os que condenam todo o processo de conhecimento formal nesta etapa. (Ostetto, 2002). Outros discutem a questão da qualidade nesta etapa educativa (Moss, Dahlberg, \& Pence, 2003). Há também poucas contribuições sobre a formação dessas/ es professoras/es (Becchi, 2003; Formosinho \& Kishimoto, 2002).

Rocha (1999) propôs que se temos uma nova concepção de infância, deveríamos construir uma pedagogia da infância. A referida autora faz a proposta, mas não indica caminhos para tal construção. A partir disto, outras questões surgem: o que há de diferente e comum nos saberes dos (as) professores/as de crianças e outros (as) professores/as? Quais as especificidades no trabalho com crianças?

Há um consenso na literatura sobre a formação dos professores que os saberes docentes são constituídos para e pela docência (Charlot, 2000, 2005; Cunha, 1999; Sacristan, 1995; Schon, 2000; Soëtard, 2004; Tardif, 2002; Tardif \& Lessard, 2005; Tardif \& Zourhlal, 2005). Neste sentido, resgatam-se pesquisas recentes que investigaram quais os saberes necessários para a docência na educação infantil. Souza, 2005, por exemplo, partiu da premissa de que as pessoas não nascem com competências necessárias para educar crianças. Para ela, o educador de crianças deve desenvolver características pessoais e profissionais para desempenhar um bom trabalho na docência com crianças. Esta pesquisa investigou quais seriam estas características e conhecimentos na opinião das professoras de educação infantil.

As principais características que foram verificadas são afetividade, compromisso, formação e senso de humor. A característica afetividade, segundo as professoras entrevistadas, está relacionada a ter paciência, ser carinhosa e gostar de criança. Estas características podem ou não estar associadas à concepção de maternagem. Souza infere que a categoria afetividade está "relacionada às abordagens teóricas que propõem que as demonstrações de sentimentos consolidam vínculos entre criança e adulto e oportuniza à criança as suas descobertas, a capacidade de se desenvolver e de estabelecer interações com outras crianças" (Souza, 2005, p.42).

Já a categoria formação originou-se das palavras que compõem a ideia das características referentes às questões de formação acadêmica e habilidades. A categoria senso de humor está vinculada à alegria, diversão e extroversão. Percebe-se que há uma comparação com as características comuns impostas às crianças. Já a categoria compromisso implica ser criativa, responsável e habilidosa. Na questão a respeito dos os conhecimentos necessários para a docência com crianças pequenas, foram identificadas quatro categorias: conhecimentos acadêmicos, conhecimentos sobre a criança, conhecimentos gerais, conhecimentos sobre o cuidar.

$\mathrm{Na}$ categoria "conhecimentos acadêmicos", destacou-se a área de Psicologia, sobretudo as questões do desenvolvimento infantil, juntamente com teorias da infância, sem precisar as áreas dessas teorias.

Conhecimentos sobre higiene, segurança, cuidados básicos foram itens que fizeram parte da categoria cuidar. Os conhecimentos gerais foram relacionados a conhecimentos de histórias infantis, seguidas por música, atualidades. Em outro trabalho relativo à mesma problemática, porém especificando mais a docência com a idade de 0 a 3 anos, Fischer (2007) investigou a concepção dessas professoras, sobre os saberes necessários para uma "boa professora" nesta faixa etária. Neste estudo, foram identificados dois tipos de saberes: pessoais e profissionais.

Os saberes pessoais são aqueles constituídos pelas experiências dos sujeitos e formados de vários outros saberes (Tardif, 2002). As palavras e expressões desta categoria foram: paciência, carinho, criatividade, entre outras.

A categoria saberes da formação profissional, que segundo Tardif(2002) são os saberes transmitidos pelas instituições de formação de professores, são eruditos e construídos pelos grupos sociais produtores de saberes. $\mathrm{O}$ saber profissional mais citado foi: conhecimento sobre desenvolvimento infantil. Percebe-se, nestes dois trabalhos, uma imprecisão nas respostas, o que denota uma dificuldade das professoras pensarem sobre o seu próprio trabalho. Talvez isto esteja relacionado à complexidade da formação da identidade da professora de crianças, principalmente daquelas que trabalham com crianças em idade de 0 a 6 anos. Ser professora da infância tem em comum vários aspectos de qualquer docente: saber ouvir, cultivar hábitos de leitura e produção de textos, gostar de se informar, ter habilidade para falar, conhecer profundamente seus conteúdos etc.

Consideramos pertinente ainda a busca pelas especificidades do docente da educação infantil, levando em conta que as investigações neste campo ainda são incipientes, sobretudo na faixa etária de 0 a 3 anos.

\section{Referências bibliográficas}

Ariès, P. (1981). História social da criança e da família. Rio de Janeiro: Zahar.

Becchi, E. (2003). Por uma pedagogia do bom gosto. In E. Becchi \& A. Bondioli (Orgs.), Avaliando a pré-escola: uma trajetória de formação de professoras (pp.123-137). Campinas: Editores Associados. 
Charlot, B. (2000). Da relação com o saber: elementos para uma teoria. Porto Alegre: Artes Médicas Sul.

Charlot, B. (2005). Relação com o saber, formação dos professores e globalização. Porto Alegre: Artmed.

Colbari, A. L. (1995). Ética do trabalho. São Paulo: Letras \& Letras.

Cunha, M. I. (1999). Profissionalização docente: contradições e perspectivas. In Veiga, I. P. A. ; Cunha, M. I.(Orgs.), Desmistificando a profissionalização docente (pp.127-148). Campinas: Papirus.

Dayrell, J. (2003). O jovem como sujeito social. Revista Brasileira de Educação, (24), 40-52.

Dubet, F. \& Martuccelli, D. (1999). À l'école, Sociologie de l'expérience scolaire. Paris: Seuil.

Ferreira, M. (2002). Criança tem voz própria. A Página da Educação, 11(117), 35. Acesso em 10 de outubro, 2006, em http:// www.apagina.pt/arquivo/Artigo.asp? ID=2139

Fischer, M. A. (2007). Concepção das professoras de crianças de 0 a 3 anos sobre os saberes necessários para ser um boa professora de bebês. Dissertação de Mestrado, Programa de Pós-Graduação em Educação, Universidade do Vale do Iajaí, Itajaí, SC.

Formosinho, J. O. \& Kishimoto, T. M. (Orgs.). (2002). Formação em contexto: uma estratégia de integração. São Paulo: Pioneira Thomsom Learning.

Heywood, C. (2004). Uma história da infância. Porto Alegre: Artmed.

Melucci, A. (2004). O Jogo do eu: a mudança de si em uma sociedade global. São Leopoldo: Unisinos.

Moss, P., Dahlberg, G., \& Pence, A. (2003). Qualidade na educação da primeira infância. Porto Alegre: Artmed.

Ostetto, L. E. (2002). Educar e cuidar: questões atuais sobre educação infantil no Brasil. São Paulo: Cortez.

Pais, J. M. (1993). Culturas juvenis. Porto: Imprensa Nacional Casa da Moeda.

Peralva, A. (1997). O jovem como modelo cultural. Revista Brasileira de Educação - Juventude e Contemporaneidade, (n. spe., 5-6), 15-36.

Rocha, C. E. A. (1999). Pesquisa em educação infantil no Brasil. Florianópolis: NUP.

Sacristan, J. G. (1995). Consciência ação sobre a prática como libertação profissional dos professores. In A. Nóvoa (Org.), Profissão Professor (2a ed., pp. 64-91). Porto: Porto.

Sarmento, M. J. (2003). O estudo de caso etnográfico em educação. Braga: Centro de Estudos da Criança, Universidade do Minho.

Sarmento, M. J. (2005). Gerações e alteridade: interrogações a partir da Sociologia da Infância. Educação e Sociedade, 26(91), pp. 361-378.

Schon, Donald. A. (2000). Educando o profissional reflexivo. Porto Alegre: Artes Médicas.

Soëtard, M. (2004). Ciência(s) da educação ou sentido da educação? A saída pedagógica. In J. Hoyssaye, M. Fabre, M. Soëtard, \& D. Hameline (Orgs.), Manifesto a favor dos pedagogos (pp.47-69). Porto Alegre: Artmed.

Souza, L. C. (2005). Os saberes dos professores de educação infantil: características, conhecimentos e critérios. Dissertação de Mestrado, Programa de Pós-Graduação em Educação, Universidade do Vale do Itajaí, Itajaí, SC.

Sposito, M. P. (1997). Estudos sobre juventude em educação. Revista Brasileira de Educação - Juventude e Contemporaneidade, (n.spe., 5-6), 37-52.
Tardif, M. (2002). O trabalho docente, a pedagogia e o ensino. In M. Tardif, Saberes docentes e formação profissional ( $3^{\mathrm{a}}$ ed., pp. 112-149). Rio de Janeiro: Vozes.

Tardif, M. \& Lessard, C. (2005). O trabalho docente (2a ed.). Petrópolis, RJ: Vozes.

Tardif, M. \& Zourhlal, A. (2005). Difusão da pesquisa educacional entre profissionais do ensino e círculos acadêmicos. Cadernos de pesquisa, 35(125), 13-35.

Varela, J. \& Uria-Alvarez, F. (1992). A maquinaria escolar. Revista Teoria e Educação, 6, 68-96.

Weber, M. (1982). Ensaios de sociologia. Rio de Janeiro: Guanabara.

Zaluar, A. (1985). A máquina e a revolta. São Paulo: Brasiliense.

Cleber Fabiano da Silva é graduado em Letras pela Universidade da Região de Joinville e mestrando em Educação pela Universidade do Vale do Itajaí (UNIVALI). Endereço para correspondência: Rua 1931, n.19, apto 34.

Centro. Balneário de Camboriú/SC. Cep 88.330.828. E-mail: cleberprofessor@yahoo.com.br

Tânia Regina Raitz é graduada em Ciências Sociais pela UFSC, Mestre em Sociologia Política pela UFSC, Doutora em Educação pela UFRGS. É professora do Mestrado em Educação na Universidade do Vale do Itajaí (UNIVALI) e coordena o grupo de Pesquisa Educação e Trabalho. Endereço para correspondência: Rua Acelon Pacheco da Costa, 231, Bloco B, apto 407. Bairro Itacorubi. Florianópolis/SC. CEP 88034-040. E-mail: floraitz@uol.com.br

Valéria Silva Ferreira é graduada em Pedagogia pela UNIVALI, mestre em Educação pela UNIVALI, doutora em Psicologia da Educação pela PUC-SP. É professora do Mestrado em Educação na Universidade do Vale do Itajaí (UNIVALI) e coordena o grupo de Pesquisa Contextos educativos e práticas docentes. Endereço para correspondência: Rua Alexandre Alexius Reiser, 283. Ressacada. Itajaí/SC. CEP 88.307.420. Email: v.ferreira@univali.br

\section{Desafios da Sociologia da Infância: uma área emergente} Cleber Fabiano da Silva, Tânia Regina Raitz e Valéria Silva Ferreira

Recebido: 07/06/2008

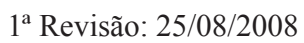

Aceite final:26/03/2009 